\title{
A gestão democrática em debate: O programa LEADER e a sua relação com a sociedade civil local
}

Debating Democratic Management: The LEADER program and its relation with local civil society

La gestion démocratique en débat : le programme LEADER et sa relation avec la société civile locale

\section{Óscar José Rover e Maria Adosinda Henriques}

\section{OpenEdition}

\section{Journals}

Edição electrónica

URL: http://journals.openedition.org/rccs/905

DOI: $10.4000 /$ rccs. 905

ISSN: 2182-7435

\section{Editora}

Centro de Estudos Sociais da Universidade de Coimbra

Edição impressa

Data de publição: 1 Outubro 2006

Paginação: 117-137

ISSN: 0254-1106

Refêrencia eletrónica

Óscar José Rover e Maria Adosinda Henriques, «A gestão democrática em debate: O programa LEADER e a sua relação com a sociedade civil local », Revista Crítica de Ciências Sociais [Online], 75 | 2006, colocado online no dia 01 outubro 2012, criado a 01 maio 2019. URL : http:// journals.openedition.org/rccs/905; DOI : 10.4000/rccs.905 


\section{OSCAR JOSÉ ROVER}

\section{MARIA ADOSINDA HENRIQUES}

\section{A gestão democrática em debate: O programa $L E A D E R$ e a sua relação com a sociedade civil local}

Parte-se da discussão do Programa de Iniciativa Comunitária LEADER da União Europeia para regiões rurais, analisando em que medida, no caso português, a autonomia local na definição das estratégias e projectos é positiva para os territórios locais, ou apenas favorece alguns actores destes territórios, não valorizando suficientemente os princípios orientadores do referido Programa, através de práticas de inclusão de grupos mais necessitados e desorganizados. A reflexão sobre o LEADER no contexto português é susceptível de extrapolação para outros contextos locais. Em geral, se é verdade que as práticas de democracia participativa podem significar um contributo para o desenvolvimento das populações locais, em particular das mais desorganizadas e necessitadas, é igualmente demonstrável, por outro lado, que o argumento da democracia e do desenvolvimento serve muitas vezes à reprodução local de práticas de dominação e de desigualdade sociais.

\section{Introdução}

Este artigo propõe-se reflectir sobre o "Programa de Iniciativa Comunitária: Ligação Entre Acções de Desenvolvimento da Economia Rural" (PIC LEADER $)^{1}$, a propósito de um tema muito citado, mas aparentemente pouco discutido no âmbito da relação Estado-sociedade civil em Portugal: a autonomia democrática.

A autonomia dos territórios e dos actores sociais locais é apresentada nos documentos oficiais e na argumentação de técnicos e políticos como um aspecto central na prossecução dos princípios e objectivos do LEADER. No entanto, a restrição da autonomia das Associações de Desenvolvimento Local $(\mathrm{ADL})^{2}$ é citada diversas vezes como algo que vem ocorrendo, ou

1 Ao longo deste artigo, quando estiver a falar-se do conjunto deste programa, designar-se-á apenas por "Leader".

2 Segundo definições do Leader as ADL são as institucionalidades locais de articulação e integração inter-organizacional e inter-institucional. Elas seriam, em tese, as instâncias institucionais de gestão coordenada do desenvolvimento local. Esta é uma das questões centrais que estará em análise neste texto. 
para que apontam as novas orientações das políticas públicas para o desenvolvimento rural.

O programa LEADER é considerado pela maioria dos seus interlocutores como inovador e os seus princípios, objectivos, estratégias e metodologias como uma importante iniciativa no âmbito da política pública de desenvolvimento rural. Apesar de os estudos rurais há muito chamarem a atenção para a construção de acções de desenvolvimento que assinalem as especificidades locais, socorrendo-se de mecanismos de valorização de produtos tradicionais e de recursos produzidos e irrepetíveis, como são a paisagem, os modos de vida, a sociabilidade e os recursos patrimoniais de várias naturezas, estas questões só foram incorporadas no discurso oficial em Portugal por influência das políticas de integração europeia (Henriques, 2002).

Com a introdução do LEADER no início da década de 1990, as perspectivas territoriais para o desenvolvimento local, e não apenas as de um ou outro sector da economia, ganham perfil de políticas públicas ${ }^{3}$ para além do discurso quanto à sua importância e obtêm recursos financeiros para a sua realização em toda a Europa. O LEADER apresenta-se como um programa preocupado com a acção integrada para o desenvolvimento de regiões essencialmente rurais, ${ }^{4}$ onde aparecem como princípios e orientações gerais o seu perfil integrador de políticas, actores, acções e projectos locais; a sua abordagem de desenvolvimento endógeno ou de baixo para cima; bem como a sua orientação no sentido de garantir a valorização do conhecimento e autonomia locais (Henriques, 2002).

Com o desenvolvimento do Programa nos últimos anos, algumas perspectivas apontam para uma restrição da autonomia na estruturação das acções de desenvolvimento local. Esta restrição é indicada por alguns como potencialmente redutora das dinâmicas de criatividade e inovação que marcaram até agora a estruturação do programa. Isto iria, segundo esta perspectiva, restringir o potencial de desenvolvimento endógeno na construção dos projectos de desenvolvimento local, além de limitar a capacidade de garantir uma ampla integração de actores, políticas, acções e projectos.

Reforça-se neste artigo, portanto, a necessidade de garantir um nível forte de participação às populações locais na organização do seu processo de desenvolvimento. Isto permitir-lhes-ia gerir de forma participada a sua inserção em dinâmicas supra-locais de desenvolvimento e aumentar

\footnotetext{
${ }^{3}$ Vale a pena ter em conta que apesar da qualidade das orientações e de muitos resultados deste programa, a sua importância em termos de recursos financeiros é pequena, por exemplo se comparado com aqueles utilizados em políticas sectoriais, nomeadamente, para o mundo rural, a PAC (Política Agrícola Comum).

${ }^{4}$ Este tipo de região é aqui compreendida dentro do enquadramento dado pela OCDE (1994).
} 
a sua autonomia. Neste sentido, não é nova a percepção de que os processos de globalização económica e de financiarização da economia têm vindo a restringir a margem de manobra de decisões a nível local para o desenvolvimento em geral e para o rural em particular. Justamente por isto, também não é nova a necessidade de níveis mais avançados de organização local para fazer frente a estes processos, permitindo que os diferentes locais não sejam tomados apenas como vítimas de processos globais (Rover, 2004).

Assim, o que se põe em questão e se reforça como necessidade neste artigo é uma maior capacidade de organização e autonomia das populações locais para formular as políticas e as estratégias organizativas para o seu desenvolvimento futuro. Não é a autonomia de uma ou outra organização que se considera como central para garantir um processo autónomo de desenvolvimento. É importante esclarecer que autonomia não é entendida como sinónimo de plena liberdade de acção, mas como processo de negociação, como capacidade para a luta política na defesa de interesses de uma organização, grupo social ou população de um território específico.

Sem deixar de ter em conta outras dimensões, propõe-se a autonomia como um conceito político e de ampliação da democracia (Held, 1986; Chauí, 1990; Castoriadis, 1992; Amaral, 2002). Assim, no contexto do programa LEADER, propõe-se que a autonomia nos territórios locais deva significar uma efectiva democratização das políticas públicas orientadas para as suas populações. A democratização da relação Estado-sociedade civil organizada, bem como da criação de oportunidades às populações mais necessitadas e menos organizadas será o objecto principal deste artigo. Considerar-se-ão os avanços históricos visíveis na actuação das ADL, do programa LEADER e demais actores organizados no meio rural de Portugal. Ponderar-se-á sobre os caminhos que actualmente se sugere para a continuidade de políticas de desenvolvimento com este perfil, enunciando alternativas no sentido da realização efectiva dos princípios e objectivos que orientam o LEADER.

Inicia-se este trabalho, portanto, com uma reflexão a partir da teoria da democracia e, neste contexto, da autonomia democrática. A partir desta abordagem, indicam-se os principais limites para o avanço efectivo de uma democracia participativa com autonomia. Procura-se indicar algumas acções para o avanço do desenvolvimento local, particularmente na incorporação dos grupos sociais mais necessitados e menos organizados. Reflecte-se ainda, a partir de documentos e discursos de actores sociais e políticos envolvidos com o programa LEADER, sobre questões que envolvem a relação Estado-sociedade civil e a autonomia dos diferentes actores e territórios locais em 
Portugal. Por fim, indica-se a necessidade de projectar acções que forjem a ampliação da autonomia dos actores sociais e dos territórios locais, procurando minimizar o privilégio de algum actor social específico, o centralismo político e o autoritarismo tecnocrático.

\section{Democracia, participação e autonomia: uma reflexão teórica}

As teorias recentes que se referem à democracia abordam a polarização entre duas vertentes: a elitista e a participacionista. Destas vertentes decorrem diversas construções teórico-práticas. A reflexão teórica que propomos concentrar-se-á na vertente participacionista, porque é nela que se situa o debate sobre a autonomia democrática.

$\mathrm{Na}$ vertente participacionista, que aprofunda a discussão dos limites da democracia representativa e propõe alternativas a estes limites, coloca-se a participação social como questão de fundo da dimensão institucional dos processos de tomada de decisão e gestão das questões públicas. No avanço da perspectiva participativa estruturam-se diversas institucionalidades, formulando novos procedimentos e aprendizagens democráticas, a partir dos quais se evidenciam também limites, seja no referente à escala territorial, à vontade política de governantes, à apatia da população, à formação para actuação em dimensões complexas da gestão pública, ou ainda à reprodução de práticas políticas tradicionais. O limite da escala territorial da gestão não se coloca para o desenvolvimento local, que é visto como o espaço teoricamente ideal para o exercício da democracia participativa. Os outros variam em ocorrência e intensidade conforme os diferentes locais, em cada um deles exigindo estudos empíricos específicos.

No quadro da democracia participativa, a participação dos cidadãos nos processos de decisão e execução das políticas públicas coloca-os como agentes activos do processo de desenvolvimento da cidadania (Held, 1986, Chauí, 1990). A constituição de modelos autónomos de gestão das políticas públicas territoriais é apresentada como o ponto de estrangulamento nas discussões da teoria democrática participativa. Isto ganha particular ênfase, no que se refere à relação entre Estado e cociedade civil, no rompimento com modelos autoritários de construção das políticas públicas, de modo a superar o favorecimento de grupos organizados com interesses específicos, bem como a beneficiar os grupos mais desorganizados e desfavorecidos. Particularmente neste último caso, e relativamente à gestão das políticas públicas em escalas mais amplas ou locais, o papel dos "cidadãos comuns" é visto como "não apenas limitado, mas frequentemente retratado como uma intrusão indesejada no funcionamento tranquilo do processo 'público de tomada de decisões'” (Borba e Seibel, 1998). 
Há já três décadas que se estuda e indica a participação ao nível local como algo que vai além de uma perspectiva de ampliação da democracia, como factor de maior eficiência na escolha e prossecução de acções para o desenvolvimento. Ignacy Sachs (1986) realça a necessidade de um planeamento participativo em territórios rurais quando se refere à organização de um modelo a que chamou "ecodesenvolvimento". Afirma que um trabalho destes "não terá bom êxito sem a iniciativa, o empenhamento e a imaginação populares necessárias à detecção correcta dos objectivos sociais e à clarificação de soluções específicas exequíveis" (ibid.: 115). No contexto do debate sobre a eficácia das estratégias de planeamento, Vieira (1995) afirma que se desmistificou a persistência de uma visão tecnocrático-autoritária, que não assume de maneira convincente a participação da sociedade civil organizada. Para além deste ponto de vista, quer seja por uma perspectiva de ampliação da democracia, quer mesmo da eficiência na gestão das políticas públicas de desenvolvimento local, há hoje concepções e experiências concretas que demonstram a importância da criação de mecanismos efectivos de participação de grupos locais menos organizados.

Existe um amplo consenso relativamente à necessidade da participação para a construção de processos de planeamento do desenvolvimento local, por distintas razões: por preocupações democráticas, por permitir escapar a formas de autoritarismo, ou por procurar maior eficácia nos processos de gestão municipal. A participação tornou-se um "lugar comum" no discurso de diversas lideranças políticas e sociais locais. Fica a questão de saber, no entanto, se estas motivações de ampliação da participação apontam para uma maior autonomia das pessoas e grupos locais ou para a manutenção de práticas de dominação políticas e económicas. Discutindo esta questão, Chauí (1990) apresenta a noção de "ilusão da participação", no âmbito da qual aparecem cidadãos isolados, privatizados e despolitizados, imaginando que a expressão em público das suas angústias, dos seus medos e dos seus desejos, os converteria em sujeitos políticos activos. Como se o desabafo pudesse superar a impotência sócio-política no exacto momento em que a deixa aparecer em público. Acresce que o processo de despolitização só será eficaz se também produzir o sentimento da participação, ainda que ilusória. É neste contexto que a autora propõe a noção de autonomia como central, na medida em que redefine o sentido de representação e participação. Entendidos desta forma, os conceitos de autonomia e participação estão vinculados um ao outro, pois sem participação não se constrói autonomia e sem autonomia a participação é apenas ilusória. 
Em processos de desenvolvimento local, ao introduzir-se dinâmicas de planeamento participativo, torna-se evidente a necessidade da passagem do exercício de poder de um plano personalista (v.g.: por parte do presidente de câmara) para um plano institucional, gerando-se dinâmicas participativas intra e inter-organizacionais, além de dinâmicas que utilizam metodologias participativas para envolver cidadãos menos vinculados às dinâmicas organizativas pré-existentes. Isto pressupõe uma dinâmica dualista de democratização (Chauí, 1990; Held, 1986; Santos, 2002a), relativamente às estruturas do Estado (tanto na esfera central como na local do poder estatal) e da sociedade civil, estruturando novas dinâmicas organizativas, estabelecendo novos formatos de participação e constituindo novos arranjos político-institucionais que ampliem a esfera pública. Trata-se de uma dinâmica dualista de democratização que procura o exercício da cidadania de uma forma activa, na qual "a sociedade civil e cada um dos seus componentes, tornados sujeitos conscientes e activos de seu próprio desenvolvimento, são capazes de redefinir o papel do Estado" (Arruda, 1997: 09). Isto remete para uma noção de sujeitos individuais e colectivos autónomos.

Held (1986) sugere que só uma circunscrição institucional da autonomia livraria a democracia participativa das desigualdades e restrições impostas por formas de apropriação privada. Já Chauí (1990: 302), referindo-se à autonomia como uma articulação entre representação e participação, refere que "autonomia é a posição de sujeitos (sociais, éticos, políticos) pela acção efectuada pelos próprios sujeitos enquanto criadores das leis e regras da existência social e política". Aponta para a autonomia de sujeitos que, compreendendo o curso da história, têm capacidade para transformar o seu percurso. Para Chaú, autonomia não é o modo de ser da sociedade e da política, é sim, luta política. Amaral (2002: 301) define autonomia "pelo reconhecimento da individualidade do ser de que é predicado e pelo direito correlativo que a ele assiste de viver esta individualidade e de decidir, em modos significativos, da sua própria vida”.

Sujeito ou actor social autónomo, portanto, é aquele que, apesar dos constrangimentos externos à sua acção, define rumos de relação com o contexto em que se insere e reconstrói a sua história a partir da negociação entre as suas necessidades e procuras, por um lado, e as orientações e constrangimentos impostos pelo contexto em que se insere, por outro.

O que se põe em questão aqui, portanto, é a necessidade de se efectivar dinâmicas autónomas de desenvolvimento local. Isto implica ampliar a capacidade dos sujeitos sociais, para que se constituam como sujeitos autónomos, ampliando também a sua capacidade de participar e negociar as decisões sobre os rumos do processo de desenvolvimento local em que estão inseri- 
dos. A participação que venha a estruturar-se nesta perspectiva não pode ser vista apenas como uma participação consultiva e delegativa, mas como uma participação activa, para não se produzirem - ainda que de forma subtil - novos processos de dominação. É possível afirmar de antemão que, em nome do desenvolvimento local e da participação, se opera em muitos territórios locais a reprodução em menor escala de lógicas de dominação evidentes em escalas mais amplas. Acredita-se que, ao problematizar estas questões, se contribui para a clarificação do tipo de dominação ou de emancipação que se coloca em diferentes casos.

Avançar para novas dinâmicas organizativas (partindo do tecido associativo local existente) que se forgem com diferentes níveis de autonomia, pode significar um expressivo avanço no desenvolvimento local. Uma autonomia que não pode dizer respeito a um ou poucos actores sociais, políticos ou económicos, mas que, em vez disso, procura atingir cada cidadão do local. Afinal, os processos participativos não se conseguem pela benevolência de algum actor social ou político, antes se estruturam a partir de interesses diversificados, sejam eles individuais, corporativos, universais. A participação é "em essência, autopromoção e existe enquanto conquista processual" (Demo, 1993).

Sobre esta questão, Covas (2004: 190-1) defende a necessidade de "aumentar a massa crítica de atribuições e competências ao nível local-regional" como uma condição para a delimitação de um espaço público de identidade e motivação endógena territorial e para uma programação pública mínima. Ele afirma que "sem uma massa crítica de atribuições e competências descentralizadas nos planos local e regional, e os recursos correspondentes, o espaço público deixa de suscitar o debate contraditório e perde relevância política". Torna-se fácil aceitar a necessidade de ampliar as competências e atribuições locais quando se considera os diversos estudos realizados contemporaneamente, por exemplo, sobre o capital social (Putnam, 1996; Abu-El-Haj, 1999; Abramoway, 2003). Ampliar as competências e atribuições locais, segundo Covas (2004: 196), amplia as capacidades de realizar de forma integrada as "funções nobres de planeamento, prospectiva e avaliação, PPA" (sic).

A interrogação de fundo neste trabalho e neste contexto, prende-se com o papel das associações ligadas ao LEADER, quer seja perante as políticas de integração europeia, quer na relação com o Estado nacional e local (trata-se de uma relação de simples absorção das políticas estatais ou de negociação efectiva a partir dos interesses locais?), quer ainda ao nível de representação que muitas vezes dizem ter dos interesses da população do território local. 


\section{Descrição e reflexão sobre a organização do programa LEADER}

A partir de 1987, assiste-se a uma viragem na visão sobre o desenvolvimento rural nas políticas europeias. É assim que a comunicação europeia de 1988 sobre o "Futuro do mundo rural" apresenta a temática do desenvolvimento rural numa óptica territorial abrangente. A redução das disparidades regionais, objectivo, explicitado no Tratado de Maastricht, de 1992, para o qual a intervenção nas áreas rurais era essencial, vem evidenciar a importância e necessidade de novas políticas de desenvolvimento rural. No âmbito destas políticas surge o PIC LEADER.

O programa LEADER teve início em 1991 com o LEADER I e desenvolve-se até hoje, com perspectiva de, como programa, se encerrar em 2006. Divide-se, basicamente, em três etapas: o LEADER I, entre 1991 e 1994; o LEADER II, entre 1995 e 2001 e o LEADER + que funciona até hoje dando continuidade aos anteriores e deverá seguir até 2006.

O programa surge como uma iniciativa comunitária, inovadora na sua perspectiva de actuação, sendo que há alguns aspectos principais que lhe estão associados: ser uma intervenção feita numa perspectiva bottom-up, instituindo o regime de parceria e definindo um conjunto de medidas elegíveis que privilegia as áreas mais débeis, reforçar a multifuncionalidade do espaço rural, valorizar economicamente as PME, acentuar a questão da qualidade e da especificidade locais e realçar a importância do funcionamento em rede e da utilização de novas tecnologias de informação. Na sua actuação, é dada especial relevância aos conceitos de inovação, demonstratibilidade e transferibilidade.

Trata-se de um programa concebido para regiões essencialmente rurais (OCDE, 1994), onde vários indicadores de desenvolvimento se apresentam normalmente abaixo dos observados em regiões essencialmente ou medianamente urbanas. São áreas que poderiam ser enquadradas no que Moreira (2001) denomina de "regiões ou territórios desfavorecidos". Diniz e Nogueira (2002: 257), usando o conceito de "mundo rural" da União Europeia e da OCDE, afirmam que este "representa cerca de $80 \%$ do território comunitário e nele habitam e/ou desenvolvem a sua actividade mais de $50 \%$ da população total da União Europeia”. Estas regiões, especialmente as situadas em zonas fronteiriças mais distantes dos centros urbanos, são as que historicamente ficaram à margem das possibilidades mais efectivas de desenvolvimento sócio-económico (Vasquez Barquero, 2004). 


\subsection{O LEADER em Portugal}

No caso de Portugal, mesmo tendo em conta a diversidade regional, as regiões mais litorais foram as mais favorecidas historicamente no acesso a bens e serviços públicos e outros efeitos do desenvolvimento. Ao contrário, as regiões mais interiores do território, mais rurais, foram as menos favorecidas. Dentro deste rural amplo, o "rural profundo", mais agrícola, mais marcado pela agricultura familiar menos integrada no mercado, foi e continua a ser o espaço menos atingido pelas políticas e benefícios do desenvolvimento.

No que se refere ao LEADER, ele atingiu 20 territórios regionais na sua primeira versão (o LEADER I), 48 territórios regionais no LEADER II (Thirion e Cavaco, s/d) e 52 territórios no LEADER +. Desde o LEADER II a quase totalidade dos territórios rurais portugueses está abrangida na actuação deste programa ( $89 \%$ ), com cerca de $35 \%$ da população portuguesa (Diniz e Nogueira, 2002: 260).

Durante o LEADER I evidenciou-se o aproveitamento das potencialidades ao nível local: no âmbito organizativo o LEADER possibilitou que grupos locais organizados e atentos ao significado desta nova oportunidade tomassem as iniciativas conducentes à realização de acções que consideravam importantes para o seu desenvolvimento. É no contexto do LEADER I que surge grande parte das organizações e iniciativas de desenvolvimento local em Portugal (OIDL), o que, em algumas situações, gera um contraponto de poder às lógicas já institucionalizadas até então. A maior parte das ADL LEADER associam instituições públicas e privadas. As autarquias (Câmaras Municipais e Juntas de Freguesia) constituem o tipo de entidade mais representada. Entre as associações privadas contam-se as que têm tradição de intervenção nos meios rurais: IPSS (Instituições Particulares de Solidariedade Social), Cooperativas Agrícolas, Associações de Produtores, Associações Empresariais, Associações Humanitárias, Ligas de Amigos, Comissões de Melhoramentos, Escolas Profissionais e outras organizações sem fins lucrativos reconhecidas como parceiros sociais e representativas da sociedade civil em meio rural. Esta participação é alargada em alguns casos a pessoas individuais, em outros, a organismos públicos.

No campo económico e produtivo, através de acções ligadas ao turismo rural e artesanato, desenvolveram-se iniciativas que, além de suscitar novas dinâmicas de organização, atenderam a uma procura dos consumidores urbanos, desejosos de alternativas de lazer, entretenimento, contacto com a natureza e com a sociedade rural. O LEADER I representou o aproveitamento de um potencial latente, pela criação de OIDL ou de projectos de tipo novo, beneficiando a população rural situada nas vilas urbanizadas dos 
territórios beneficiados e favorecendo os grupos locais que tinham mais clara percepção das oportunidades organizativas e de negócio.

Quando se fala do LEADER entre os actores de desenvolvimento local de Portugal é comum, apesar das considerações críticas, ouvir-se falar da sua "capacidade de mobilização e inovação, permitindo a emergência de novos laços sociais e formas de organização local" (Thirion e Cavaco, $\mathrm{s} / \mathrm{d}$ : 7). Segundo estes autores, isto deve-se à orientação prática do LEADER que foi caracterizada por uma confiança nos actores locais, uma autonomia para elaborar uma estratégia de desenvolvimento territorial e implementar projectos e uma responsabilização dos actores sociais locais. Segundo Melo (1996: 11) "terá sido Portugal o país onde se verificou a maior fidelidade à filosofia original do LEADER", referindo-se à abertura às pequenas associações locais e aos "pequeníssimos projectos de centenas de residentes em meio rural".

Qual seria então esta filosofia original? Segundo um responsável pela direcção do programa, em palestra onde realizava um balanço do LEADER, os princípios e a metodologia definidos para o funcionamento do LEADER procuram "dar à sociedade civil uma palavra importante, definindo competências em diferentes níveis, de modo a que ela assuma a responsabilidade pelo desenvolvimento das zonas rurais" (Carrinho, 1996: 14). Mais adiante, o mesmo autor afirma: "é uma metodologia [...] que dá resposta às necessidades manifestadas pela própria comunidade a que o programa se dirige". Nestas afirmações está implícita uma vertente marcante da abordagem LEADER que é a busca de uma acção de baixo para cima (bottom-up), ou de dentro para fora (endógena). É comum encontrar-se afirmações de que as acções de desenvolvimento local criam condições para uma ampla participação das populações locais no processo de planeamento (Carrinho, 1996; Diniz e Nogueira, 2002). De facto, uma política europeia de desenvolvimento rural que valorizasse o rural, promovesse os seus elementos diferenciadores, contra a homogeneização e especialização a que a política agrícola se tinha reduzido, tinha de ter uma base, carecia de interlocutores organizados localmente (Henriques, 2001). O problema é que muitos dos planos que orientam a acção local do LEADER foram elaborados por um grupo restrito de técnicos isoladamente ou, quando muito, em diálogo com um contingente também restrito de actores sociais.

Pondere-se, assim, que a elaboração de um plano, programa ou projecto por alguns actores sociais locais não exclui a necessidade de verificar em cada local quem realmente participa, decide sobre os planos e beneficia das políticas que se elaboram. Se o facto de desenvolver projectos e acções ao nível local permite uma maior proximidade dos problemas, necessidades e 
interesses, isto não quer dizer que necessariamente todos os problemas, necessidades e interesses sejam analisados e atendidos, quer porque não existem recursos para atender a todos, quer porque, na distribuição do poder local, as diferenças estão presentes como em outras escalas.

\section{A relação Estado - organizações sociais em Portugal e no programa LEADER}

As questões aqui levantadas não devem apontar para uma maior centralização dos processos de decisão sobre as políticas públicas, mas para a organização de processos efectivos de democratização local. Basta partir do argumento da proximidade das pessoas às decisões sobre as políticas para se tornar claro que é possível uma maior democratização nas esferas locais do poder público do que nas esferas centrais. Apesar disto, e apesar de experiências como o programa LEADER, não só o Estado continua a ter um papel decisivo na orientação dos rumos da sociedade e da economia, como o Estado central em Portugal concentra grande parte do poder de definiçãa do uso de recursos e das políticas de desenvolvimento.

Ruivo e Francisco (1998-9: 300-301), referindo-se à autonomia financeira das entidades descentralizadas em 16 países europeus, indicam que, a partir dos anos 50, quinze destes países viram diminuídas as suas despesas com o governo central em relação aos governos locais. A única excepção é Portugal. Apesar desta centralidade do Estado, tanto quantitativa quanto substancial, Reis (1995: 46) refere que a presença do Estado é multifacetada, gastando através de transferências, delegação e subcontratações. Assim, o Estado é apresentado como "uma rede de identidades diversas e não um agente de face única". O autor afirma que o "Estado" exerce cada vez menos directamente a despesa [...]. Ele representa a estrutura nuclear de decisão política e de decisão sobre a despesa pública, mesmo que não a exerça directamente. Por isso, cresce a despesa com transferências e subsídios, ou seja, despesas não executadas pela máquina estatal (ibid.: 43-4).

A iniciativa comunitária LEADER, como é sabido, é orientada para um nível de autonomia local das decisões sobre os planos, acções e projectos, restringindo a capacidade de os agentes do Estado central a controlarem. Os fundos comunitários destinados ao LEADER são atribuídos às ADL credenciadas para a gestão local dos Planos de Acção Local (PAL, designação atribuída no LEADER I e II) e Planos de Desenvolvimento Local (PDL, no LEADER +), com base em convenções locais de financiamento.

$\mathrm{O}$ apoio do Estado nem sempre serve para reforçar as ADL. Por um lado, elas assumem pertencer à sociedade civil, mas contêm em si organismos da administração local e outros que mais não são do que extensões do Estado. 
O Estado, por sua vez, relaciona-se com as associações ora tratando-as como agentes da sociedade civil, ora como agentes de execução da sua própria política definindo, para isso, as regras do jogo. Mas, ao mesmo tempo que se aproxima por considerar importante a acção das ADL na prossecução das políticas de desenvolvimento rural, tirando partido da visibilidade dessa acção, o Estado afasta-se quando elas intervêm em áreas que ele considera marginais (Henriques, 2001).

O nível de autonomia reivindicado e por vezes conquistado por muitas ADL tem gerado, da parte de responsáveis pela coordenação do LEADER no Estado central português, argumentos reincidentes sobre uma excessiva autonomia destas organizações. Afirmam que há um desconhecimento generalizado do que está a acontecer em cada território e que, havendo pouco controlo do uso dos recursos públicos nas acções locais do LEADER, devem ser estabelecidos mecanismos de maior controlo de tais acções, uma tarefa que caberia ao Estado central desenvolver. Este tipo de argumento e acções que defendem a necessidade de maior organicidade e conhecimento do que ocorre nos diferentes territórios locais tem gerado um evidente conflito entre tecnocratas do Estado central e agentes locais do LEADER quanto ao crescimento de uma burocratização das regras e funcionamento do programa.

Este perfil de confrontação dá-se, sobretudo, entre as ADL e o Estado central, pois, no âmbito local, a relação entre estas partes é mais interdependente. Das 48 entidades locais que geriam o LEADER II, 38 (79\%) eram integradas também por autarquias locais, reforçando a prática já existente no LEADER I (de 60\% para 79\%). Na gestão do LEADER + apenas uma ADL afirma não possuir alguma organização estatal ou para-estatal como parceira (CIDEC, 2004). A razão disto prende-se com o facto de necessitarem de uma componente de comparticipação financeira para a aprovação dos projectos, a qual normalmente é suportada pela administração local. Muitas vezes, são as próprias autarquias que suportam parte das despesas das ADL quando há atrasos no financiamento no âmbito do LEADER ou de outros programas comunitários em cuja gestão também colaboram (IC EQUAL; IC INTERREG; Luta Contra a Pobreza; PPDR - Centros Rurais, AGRIS, AGRO, entre outos).

Da parte das ADL, este desejo de lhes reduzir a autonomia é frequentemente interpretado como fazendo parte de uma estratégia geral do governo central no sentido da ampliação do controlo sobre a sociedade civil. Muitas delas apresentam-se como representantes de uma sociedade civil local que tem de ampliar, e não reduzir, a sua autonomia em relação ao Estado. Justificam a sua legitimidade de representação por estarem preocupadas e a 
actuar no sentido do desenvolvimento do território em que trabalham e entendem que cada organização local deve ter a garantia democrática da sua autonomia frente a outras organizações e instituições com quem se relaciona, inclusive o Estado. As ADL, em tese, mais que associações de desenvolvimento, representariam uma integração de actores sociais, políticos e económicos locais. No entanto, a decisão sobre processos e a aprovação de projectos restringe-se, com frequência, aos GAL (Grupos de Acção Local), uma vez que estes apenas submetem o seu parecer à unidade de gestão da ADL que é menos representativa que a sua assembleia geral.

É importante salientar que a prática das ADL reproduz muitas vezes as formas da administração estatal debaixo de um discurso que reivindica autonomia. A este comportamento não é alheia a precariedade de emprego do corpo técnico, a submissão a interesses políticos locais e a quase completa dependência do dinheiro público. Até a "vigilância activa" que deveria constituir um dos aspectos fundamentais da sua acção é muitas vezes prejudicada por estes condicionalismos.

Entende-se que se deverá investir no fortalecimento destas institucionalidades de modo a reforçar a colaboração entre poder estatal e a sociedade civil, criando novas esferas/poderes públicas no sentido da constituição de verdadeiras parcerias e interacção. Deverá, ainda, garantir-se a autonomia das ADL no contexto do LEADER, desde que haja mecanismos que permitam que os trabalhos que desenvolvem integrem a participação activa da população local. No entanto, num programa de abordagem territorial como o LEADER, parece restritivo que se garanta uma autonomia ampla aos grupos de acção local (GAL), que representam a equipe técnica e a coordenação do processo do LEADER, quando não há um processo efectivo de negociação entre o conjunto dos actores locais.

Em muitos territórios locais o esforço de concertação político-institucional junto das populações e organizações para construir consensos relativamente a estratégias de desenvolvimento regional e definir projectos prioritários para o seu desenvolvimento é precário na actuação dos GAL e das ADL. Falta, em suma, "uma acção mais integrada para o desenvolvimento local", tal como se refere nos princípios orientadores do programa LEADER. Autonomia como luta política implica em cada organização lutar pelo seu espaço político-institucional nos processos de desenvolvimento. O que se observa, no entanto, além de uma restrição tecnocrática em que definições estratégicas ficam sob a guarda dos GAL, é uma restrição de envolvimento e participação activa dos actores sociais mais necessitados e desorganizados.

A questão que se coloca é como construir processos autónomos localmente sem excluir grupos e actores sociais com pouco conhecimento, orga- 
nização e força política. Aqui, o direito a participar não é interpretado apenas como ideal democrático, mas como um mecanismo que garanta maior eficácia e efectividade dos processos de desenvolvimento local. Através de uma participação decisória e integrada de amplos contingentes da população local, é possível aproveitar o saber-fazer, o conhecimento detalhado da realidade e a vontade de agir dos actores sociais locais. Sem uma participação mais efectiva, os grupos mais necessitados e desorganizados não poderão expressar as suas necessidades e interesses, enquanto aqueles que possuem maior poder relacional instituído nas redes de poder local acederão a maiores benefícios. Sem um espaço efectivo de participação local para os grupos mais necessitados e desorganizados o desenvolvimento local reproduzirá em grande medida as assimetrias de poder e de exclusão de outros modelos "de cima para baixo" (top-down).

\section{O LEADER e os limites de incorporação dos grupos sócio-economica- mente desfavorecidos}

O rural profundo foi menos atingido pelo programa LEADER. Historicamente envolvidas em actividades agrícolas, com menor organização para o mercado e, certamente, mais necessitadas de apoios para produção de novas alternativas para o seu desenvolvimento económico, os agricultores familiares, de perfil supostamente menos empreendedor, ficaram maioritariamente à margem do acesso aos apoios do LEADER.

Quais seriam, então, as limitações para atingir os grupos e populações menos organizadas e mais necessitadas? Desde o LEADER I até hoje, a necessidade de uma contrapartida financeira para cada projecto a aprovar é uma limitação que os agricultores mais descapitalizados não conseguem superar, até porque faltam em muitos locais mecanismos de micro-crédito que complementem a necessária parcela de recursos próprios. Por outro lado, também é limitado o envolvimento destes grupos nas tomadas de decisões estratégicas do desenvolvimento local, quer quanto às orientações gerais, quer no que se relaciona com a selecção dos projectos a aprovar. É evidente a necessidade de um esforço institucional de discriminação positiva destes grupos. Uma tal discriminação exige a superação do preconceito relativamente às capacidades dos grupos mais necessitados e desorganizados, e um maior investimento na sua formação/capacitação.

Por vezes evidencia-se a ideia de que há os mais e os menos capazes para uma participação qualificada, como se a capacidade não se devesse a processos de aprendizagem. A visão de que há uma incapacidade na população do rural profundo (o rural mais agrícola) para gerir projectos e inovar não é recente, nem específica dos processos de desenvolvimento local. Desde a 
teoria da democracia há, no viés elitista, pensadores que propõem limitar a participação dos cidadãos ao voto justamente para, a partir dá, dar ao Leviatã, que possui o conhecimento e a legitimidade, o poder de tomar as decisões de interesse público.

Ressalve-se, relativamente às ADL LEADER, que se poderia inventariar os esforços e experiências que procuram incorporar uma maior participação da diversidade de actores sociais nos processos de desenvolvimento local. Em geral, no entanto, reconhece-se que este esforço é limitado pela ideia de que os técnicos e dirigentes já saberiam o que é importante fazer. $\mathrm{O}$ argumento destes é que não se trabalham processos participativos mais efectivos porque não existe um "espírito de participação" nas pessoas (Monteiro, 2004: 273). Na ausência de métodos adequados que qualifiquem a participação social e de resultados efectivos que motivem as pessoas a envolver-se de forma continuada em processos participativos, torna-se mais fácil justificar o desinteresse das populações pela participação. Cria-se, assim, um efeito circular de justificação da não participação: não se aprofunda a aprendizagem em metodologias participativas com o argumento do desinteresse de participação das pessoas e grupos sociais; estes, por sua vez, não participam mais por não verem ambientes efectivos de encaminhamento das suas necessidades e interesses nos espaços de participação gerados.

Não está incorporado na formação de grande parte dos agentes técnicopolíticos de DL a percepção pedagógica de que o conhecimento é sempre uma via de mão dupla, particularmente no que se refere à educação para o desenvolvimento. Nas palavras de Paulo Freire, ao contrário de uma extensão de conhecimento técnico (uma via de mão única), esta acção pode ser mais eficiente se for concebida como comunicação entre partes que possuem saberes diferentes (Freire, 1971). Esta perspectiva de troca de conhecimento sugere a necessidade de processos efectivos de educação popular, formação política sobre cidadania e direitos, e formação para a organização colectiva de interesse destes grupos. Em muitos casos, é justamente isto que poderia abrir um horizonte mais amplo às possibilidades de participação social, económica e política de uma diversidade de grupos e populações. Isto, no entanto, implicaria a definição dos agricultores familiares e dos grupos menos organizados e mais necessitados como público prioritário de actuação, previamente à valorização das suas capacidades.

Não atingir os públicos mais necessitados e desorganizados revela também, aparentemente, uma perspectiva cómoda, na medida em que permite a contratação do máximo de projectos (uma perspectiva de balcão) e, assim, conseguir uma boa execução material e financeira no relativo aos objectivos propostos e exigidos pela gestões nacional e comunitária do LEADER. De 
facto, a necessidade de responder a metas previstas para o programa faz com que as ADL não se concentrem num trabalho de formação e organização de base. Isto não só atende mais facilmente à realização de metas, mas permite também maior comodidade no trabalho técnico. As menos comprometidas em gerar espaço para os grupos mais necessitados e menos organizados certamente preferirão este tipo de caminho.

Outra explicação para muitas acções das ADL não atingirem os públicos mais necessitados e desorganizados é o facto de elas estarem directamente ligadas às autarquias locais, reproduzindo, por vezes, uma lógica de clientela, atendendo a projectos ligados aos grupos políticos e económicos dominantes no local. Estes grupos exercem um tipo de poder que os coloca mais próximos das redes de decisão das políticas locais do que outros cidadãos. Ruivo e Francisco (1998/99) citam efeitos perversos deste exercício de poder, o qual demonstra a "aceitação de um sistema e ordem sociais baseados numa carga de desigualdade", o que vem a legitimar e perpetuar a própria desigualdade. Assim, num discurso de igualdade perante a política, os que beneficiam destas lógicas de poder sentem-se entre si mais iguais que outros.

Através de métodos e procedimentos de gestão social das políticas públicas locais, há que prevenir que não se reproduza uma lógica de tutela do político-partidário e do poder relacional de grupos específicos de interesse sobre a coordenação dos processos de desenvolvimento local. Afinal, dada a cultura política instituída, é perfeitamente possível que se reproduzam ao nível local lógicas de exercício do poder político baseadas na dominação de uns e na exclusão de outros.

\section{Reflexão preliminar sobre uma possível alternativa}

Para evitar possíveis efeitos perversos da autonomia local dominada pelos GAL, o Estado central aponta a necessidade de um maior controlo das ADL. Por outro, face a um apelo democrático, muitas ADL defendem a não restrição da sua autonomia como condição da autonomia da sociedade civil e uma maior representatividade da vontade dos cidadãos. Se, em muitos casos, há um verdadeiro esforço de construir processos representativos das necessidades e vontades locais, isto não parece ser verdade para muitos outros.

Há necessidade de um controlo efectivo sobre o uso e gestão dos recursos públicos aplicados em cada local/região. Em muitas regiões há a definição por projectos que, mesmo sendo viáveis economicamente, não representam uma acção efectiva que inclua os públicos em condições económicas débeis no acesso a recursos públicos. 
Ao Estado central, do ponto de vista de uma ampliação dos processos democráticos, não compete realizar o controlo da gestão dos processos desenvolvidos em cada território local, Cabe-lhe o controlo da gestão financeira, reduzindo ao máximo as exigências burocráticas, para permitir a concentração dos esforços locais na realização dos princípios e objectivos do LEADER.

Há, no entanto, a necessidade de um controlo efectivo sobre a gestão do processo que, não sendo burocrático, deve ser um controlo social sobre o uso e gestão de fundos públicos. Mais do que controlo, afinal, entende-se que a gestão se compõe também de planeamento, direcção e organização, o que torna necessária a constituição de processos mais efectivos de gestão social do desenvolvimento local. Considera-se importante que a gestão dos fundos públicos, definição de estratégias, acções e projectos de desenvolvimento local sejam coordenadas por fóruns locais deliberativos. Estes fóruns são uma alternativa efectiva de gestão social local. Eles podem ser o resultado do aprofundamento democrático das relações entre as entidades que integram as ADL, sem que seja necessário constituir novas institucionalidades. Sugere-se com isto que há necessidade de criar métodos e instrumentos efectivos para que as decisões sobre estratégias, acções e projectos passem por fóruns deliberativos e representativos das necessidades e interesses locais. Como afirma Hespanha (2000), há necessidade de um agente legitimado para mobilizar e mediar as acções dos intervenientes, que garanta a expressão equilibrada de interesses, que evite a sobreposição de actuações e que vele pela melhor utilização de recursos.

Isto implica a integração do conjunto dos grupos e organizações locais para o diagnóstico e planeamento estratégico e participativo do desenvolvimento local, ordenando a partir daí a organização de programas e projectos, e a definição de orçamentos para o desenvolvimento. Refere-se, necessariamente, a formatos de planeamento e orçamento participativos, que, na sua organização metodológica, prevejam e criem procedimentos para a inclusão do conjunto dos grupos e interesses locais.

Seria a partir daí, num diálogo constante com o fórum local deliberativo, coordenador de todo o processo, que se constituiria a actuação técnica, viabilizando a construção, definição e priorização de projectos. Num cenário nacional em que são correntes práticas clientelísticas e de "familismo amoral" (Cabral, 2001), esta forma de ordenar um processo de construção do ambiente institucional e organizativo para construção de programas e projectos, parece responder melhor à necessidade de democratização e ampliação das autonomias na construção dos processos de desenvolvimento local. Este caminho parece atender melhor a uma lógica de definir, 
aprovar e apoiar projectos que se encaixem numa estratégia de desenvolvimento regional e não seguir um caminho de definição avulsa de projectos que podem ser escolhidos atendendo a interesses de algum grupo ou actor específico.

O que se designa aqui como fórum local deliberativo e que pode ser constituído a partir das assembleias das ADL qualificadas pela sua actuação, considera-se ser algo específico para gestão e controlo da gestão do desenvolvimento local no contexto do programa LEADER. Não se está a propor este mecanismo para um controlo geral das organizações sociais que, enquanto organizações, devem ter a sua autonomia institucional garantida. A um fórum coordenador, mais amplo, caberia a responsabilidade de produzir as directrizes estratégicas para o desenvolvimento local/regional, os critérios de acesso de diferentes grupos e pessoas a programas e projectos e os valores monetários a gastar com actividades meio, para que a maior parte dos recursos seja orientada para actividades fins. Em suma, a responsabilidade de coordenar efectivamente o processo de desenvolvimento em cada local/região.

\section{Ponderações finais}

No sentido da ampliação da autonomia democrática na relação entre Estado e sociedade civil em processos de desenvolvimento local, reforça-se a importância da integração e acção coordenada das organizações sociais já existentes no território, da dinamização de novas organizações sociais e práticas organizativas para participar activamente em acções coordenadas para o desenvolvimento local e ainda de uma relação de negociação franca e de discriminação positiva dos grupos menos favorecidos no conjunto das políticas públicas de desenvolvimento local e não apenas em políticas de carácter social. A construção de um desenvolvimento local com autonomia passa também pela identificação de necessidades e interesses comuns entre diferentes actores sócio-economicamente fragilizados e a sua organização para a satisfação destas necessidades e interesses.

Postular a mobilização da sociedade civil não é apenas estabelecer entidades capazes de receber tarefas de gestão descentralizadas pelo Estado, mesmo que o façam com maior eficiência. É, sobretudo, criar capacidade de autonomia no conjunto dos actores individuais e colectivos locais, abrindo espaços para novos experimentalismos (Santos e Avritzer, 2002), criatividades e iniciativas, "contra o desperdício da experiência" (Santos, 2002b).

O aprofundamento da democracia política, social ou económica e estas dimensões pensadas em conjunto no âmbito local, passa pela democratização e descentralização do Estado, por novas práticas de participação activa 
dos(as) cidadãos(ãs) em espaços públicos estatais ou civis, além de garantir que pessoas e grupos que ainda não se constituíram como actores protagonistas do seu desenvolvimento tenham espaço para tal.

A criação de uma diversidade enorme de associações não correspondeu ainda à expressão de um sector verdadeiramente autónomo pois está-se frequentemente perante o tratamento privado de objectivos públicos (Henriques, 2001). A própria importância da participação do Estado como parceiro, e não apenas como suporte financeiro, não é compatível com a fragilidade e dependência de muitas associações e menos ainda com as dinâmicas organizativas das pessoas em geral, dos agricultores em particular, afinal, dos grupos sócio-economicamente desfavorecidos do espaço rural.

A partir do início da década de 1990 o Programa LEADER veio reforçar em Portugal o que poderia denominar-se movimento social de desenvolvimento local. Em função do PIC LEADER, este movimento teve um suporte financeiro importante para a sua estruturação nos territórios rurais. Para avançar nas perspectivas propostas desde a origem por este movimento e pelo programa LEADER, considera-se central a sua radicalização democrática, no sentido de uma gestão social participativa, activa e autónoma. Acredita-se que apenas uma radicalização neste sentido poderá permitir que este movimento não seja dominado ao nível local por decisões tecnocráticas e por práticas de favorecimento a interesses privados, reproduzindo lógicas de dominação costumeiras em escalas supra-locais.

\section{Referências Bibliográficas}

Abramoway, Ricardo (2003), O futuro das regiões rurais. Porto Alegre: Ed. da UFRGS.

Abu-El-Haj, Jawdat (1999), "O debate em torno do capital social: uma revisão crítica", BIB, 47, 65-79.

Arruda, Marcos (1997), "Globalização e sociedade civil: Repensando o cooperativismo no contexto da cidadania ativa”, Perspectiva Económica, 32(96), 5-41.

Amaral, Carlos Eduardo P. (2002), Do Estado soberano ao Estado das autonomias: regionalismo, subsidiariedade e autonomia para uma nova idéia de Estado. Blumenau: Edifurb.

Barquero, José Á. Vasquez (2004), "Cooperación transfronteriza e integración económica: la eurorregion Galicia-norte de Portugal”. Comunicação apresentada na 2. ${ }^{a}$ Oficina de cooperação: Ampliar a Cooperação Transnacional/Programa LEADER. Melgaço, 17 a 19 de Nov. de 2004.

Borba, J.; Seibel, E. (1998), "Participação política e democratização do Estado". Lisboa: Congresso de Sociologia Econômica. 
Cabral, Manuel Villaverde (2001), “Autoritarismo de Estado, 'distância do poder' e familismo amoral - uma pesquisa em progresso”, in Amélia Cohn et al. (orgs.), BrasilPortugal: entre o passado e o futuro: o diálogo dos 500 anos. Rio de Janeiro: EMC.

Carrinho, Goulart (1996), "O LEADER em Portugal: balanço e perspectivas”, in José Portela (org.), "O LEADER em Portugal: balanço e perspectivas - palavras de Goulart Carrinho”, Série Palavra Oportuna, 2.

Castoriadis, Cornelius (1992), "O socialismo do futuro", in C. Castoriadis et al., A criação histórica. Porto Alegre: Artes e ofícios.

Chaú, Marilena de Souza (1990), Cultura e Democracia: o discurso competente e outras falas. São Paulo: Cortez Editora.

CIDEC (2004), Estudo de avaliação intercalar do programa de iniciativa comunitária de desenvolvimento rural (LEADER +): Relatório final. Lisboa: IDRHa.

Covas, António (2004), Política agrícola e desenvolvimento rural: temas e problemas. Lisboa: Colibri.

Demo, Pedro (1993), Participação é conquista - noções de política social participativa. São Paulo: Cortez.

Diniz, Francisco; Nogueira, Fernanda (2002), "Promotores públicos e privados no LEADER II: o caso das NUTS Douro e das regiões autónomas da Madeira e dos Açores", Gestão e Desenvolvimento, 11, 255-278.

Freire, Paulo (1971), Extensão ou comunicação. São Paulo: Paz e Terra.

Held, David (1986), Modelos de democracia. Belo Horizonte: Paidéia.

Henriques, Maria Adosinda (2001), "Uma alternativa associativa para o desenvolvimento rural?” 1. ${ }^{\circ}$ Congresso de Estudos Rurais, Vila Real, 16 a 18 de Setembro de 2001.

Henriques, Maria Adosinda (2002), "Globalização e integração diferenciadora dos espaços rurais”, in José Reis; Maria Ioannis Baganha (orgs.), A economia em curso: contextos e mobilidades. Porto: Afrontamento.

Hespanha, Pedro (2000), "Problemas sociais em espaço rural: políticas e atores", in Estudo de avaliação contínua do PIC LEADER II (Volume de anexos). Lisboa: DGDR /GEOIDEIA/IESE.

Melo, Alberto (1996), "Palavras breves sobre o tema do colóquio e sobre o orador", in José Portela (org.), "O LEADER em Portugal: balanço e perspectivas - palavras de Goulart Carrinho”, Série Palavra Oportuna, 2.

Monteiro, Alcides A. (2004), Associativismo e novos laços sociais. Coimbra: Quarteto. Moreira, Manuel Belo (2001), Globalização e agricultura: zonas rurais desfavorecidas. Oeiras: Celta.

OCDE (1994), Créer des indicateurs ruraux pour étayer la politique territoriale. Paris.

Putnan, Robert (1996), Comunidade e democracia: a experiência da Itália moderna. Rio de Janeiro: Editora FGV.

Rover, Oscar J. (2004), "Uma visão global sobre a aprendizagem em orçamentos participativos em contextos rurais brasileiros: limites e avanços". Seminario internacional 
Nueva Ruralidad, Transformación, Economía, Educación y Gobernabilidad, Lima/Peru, 29 e 30 de Setembro de 2004.

Ruivo, Fernando; Francisco, Daniel (1998/99), “O poder local entre centro e periferias”, Revista Crítica de Ciências Sociais, 52/53.

Sachs, Ignacy (1986), Ecodesenvolvimento: Crescer sem destruir. São Paulo: Vértice.

Santos, Boaventura de Sousa (2002a), Democracia e participação: o caso do orçamento participativo de Porto Alegre. Porto: Afrontamento.

Santos, Boaventura de Sousa (2002b), A crítica da razão indolente: contra o desperdício da experiência. Porto: Afrontamento.

Santos, Boaventura de Sousa; Avritzer, Leonardo (2002), "Introdução: para ampliar o cânone democrático", in B. S. Santos (org.), Democratizar a democracia: os caminhos da democracia participativa. Rio de Janeiro: Civilização Brasileira.

Thirion, Samuel; Cavaco, Cristina (s/d), O desenvolvimento local em meio rural face ao desafio da sustentabilidade: os ensinamentos de 10 anos da iniciativa comunitária LEADER em Portugal através de 16 cadernos temáticos produzidos no quadro das atividades da célula de animação da rede portuguesa LEADER II. Lisboa: INDE/CAL.

Vieira, Paulo F. (1995), "Meio Ambiente, desenvolvimento e planejamento", in AAVV, Meio ambiente, desenvolvimento e cidadania: desafios para as ciências sociais. São Paulo/Florianópolis: Cortez/UFSC, 45-98. 